\title{
A microbial biosensor for the microscale measurement of bioavailable organic carbon in oxic sediments
}

\author{
Frank Neudörfer*, Lutz-Arend Meyer-Reil \\ Institut für Ökologie der Ernst-Moritz-Arndt-Universität Greifswald, Schwedenhagen 6, D-18565 Kloster/Hiddensee, Germany
}

\begin{abstract}
A microbial biosensor consisting of an oxygen microelectrode with microbial cells immobilized in polyvinyl alcohol attached to the tip is described. Since the oxygen consumption of the immobilized cells is dependent on the oxidation of assimilable carbon, the biosensor allows the estimation of available dissolved organic carbon (ADOC) in sediment profiles on a microscale. Only that fraction of the ADOC can be detected which is actually respired by the test organisms. Since the biosensor works only in oxic sediments, oxygen has to be measured separately. Calibration was achieved in mineral salt medium of different oxygen content using different concentrations of carbon (glucose, acetate). The $90 \%$ response time of the biosensor was about $10 \mathrm{~s}$; within $1.5 \mathrm{~min}$ a plateau was reached, indicating that the diffusion of oxygen from the sample was in equilibrium with the oxygen consumption of the cells. Measurements with ammobilized yeast cells revealed that within the diffusive boundary layer, concentrations of ADOC increased, reaching maximum values immediately below the sediment surface. Less than $0.1 \%$ of the total organic carbon (TOC) was immediately available for microbial metabolism. Based on respiration calculated from measurements by oxygen microelectrodes in the dark, the average turnover time of $\mathrm{ADOC}$ within the upper $1 \mathrm{~mm}$ of the sediment was in the range of $50 \mathrm{~min}$.
\end{abstract}

KEY WORDS: Oxygen microelectrode Biosensor Immobilization Dissolved organic carbon Sediment

The pool of organic matter in sediments comprises different fractions which may be arbitrarily divided into (living) biomass, labile (mostly dissolved) and refractile (mostly particulate) carbon. The overwhelming proportion of the total organic carbon is resistant and undergoes only slow decomposition although it may be ultimately degraded by microorganisms. Biomass and labile carbon represent only a few percent of the total carbon pool (cf. literature cited in Meyer-Reil 1993). However, most of the turnover of carbon occurs in relation to these 2 fractions (Coffin et al. 1993). Through utilization of labile organic carbon, micro-

•E-mail: neudoerf@rz.uni-greifswald.de organisms influence the early diagenesis of organic matter in sediments to a large extent (e.g. Deming \& Baross 1993).

Although a lot of information is available concerning the total organic carbon (TOC) and total dissolved organic carbon (DOC) in marine sediments, both the TOC and DOC are only of limited significance to microbial metabolism. Indeed, it is the available dissolved organic carbon (ADOC) that microorganisms rely on to meet their requirements for energy and carbon. Since ADOC is an important parameter regulating microbial metabolism, there is an urgent demand for the determination of ADOC (Meyer-Reil 1994). The chemical analysis of assimilable organic carbon is limited by the broad spectrum of chemical compounds, and it is almost impossible to analyse all of the substrates potentially available for microbial metabolism. The development of a bioassay would be the method of choice for the measurement of ADOC.

Van der Kooij et al. (1982) and LeChevallier et al. (1993) determined ADOC by following the growth (plate counts or ATP measurements) of standardized pure cultures of heterotrophic microorganisms added to a filtered sample. Several bioassays for determining ADOC in waters were proposed by Servais et al. (1987. 1989) and Carlucci et al. (1987). These procedures depend on the filtration of water samples and reinoculation with the natural assemblages of bacteria. ADOC was followed by measurements of DOC on the one hand and bacterial biomass and mortality rate on the other hand. Nedwell (1987) determined ADOC in pore water or aqueous extracts of sediments seeded with pure cultures of bacteria by growth of test organisms. An enzymatic method which directly measured the pool of bioavailable acetate in sediments was discussed by Wellsbury \& Parkes (1995)

Microelectrodes are well-established tools to follow concentration gradients of chemical compounds with a 
high spatial resolution relevant to microbial metabolism in sediments. Oxygen microelectrodes have been used for the study of both photosynthesis and aerobic respiration (Revsbech \& Jørgensen 1986). With the knowledge of their construction, it was a logical step to provide microelectrodes with immobilized microbial cells. A microsensor for nitrate based on immobilized denitrifying bacteria has been recently described by Larsen et al. (1996). We report here on a microbial biosensor consisting of an oxygen microelectrode with immobilized microbial cells attached to the tip. This biosensor combines the advantages of the stability and fast response of oxygen microelectrodes with the advantage of respiration measurements using immobilized microbial cells. Since the oxygen consumption of immobilized microbial cells is dependent on the concentration of $\mathrm{ADOC}$, the biosensor offers the opportunity for a sensitive estimation of ADOC in aerobic sediment profiles with high spatial resolution.

As test organisms, we used 2 bacterial strains and a yeast isolated from coastal waters of the Baltic Sea using glucose-peptone agar plates. The yeast was provided courtesy of $\bar{B}$. Heideck and $\bar{F}$. Schauer íDepariment of Microbiology, Ernst-Moritz-Arndt-University Greifswald) and determined as Rhodotorula mucilaginosa. Pure cultures of the microorganisms were grown in a medium of $5 \mathrm{~g}$ tryptone and $1.5 \mathrm{~g}$ of yeast extract at a salinity of 0.7 psu at room temperature. Cells from the logarithmic growth phase were harvested by centrifugation and washed 3 times in a mineral salt medium consisting of $5 \mathrm{~g} \mathrm{NaCl}_{1} 1 \mathrm{~g} \mathrm{KCl}, 1 \mathrm{~g} \mathrm{NH} \mathrm{Cl}_{4}$, $0.5 \mathrm{~g} \mathrm{~K}_{2} \mathrm{HPO}_{4} \times 3 \mathrm{H}_{2} \mathrm{O}, 0.2 \mathrm{~g} \mathrm{MgSO}_{4} \times 7 \mathrm{H}_{2} \mathrm{O}, 0.1 \mathrm{~g}$ $\mathrm{CaCl}_{2} \times 2 \mathrm{H}_{2} \mathrm{O}$ per $1000 \mathrm{ml}$ distilled water. As a matrix for immobilization, polyvinyl alcohol (PVA; Elvanol 71 30, Du Pont, Germany) was chosen (Ramsch \& Weil 1993). A suspension of $10 \%(w / w)$ PVA solution in distilled water with the addition of $10 \%$ glycerol was gently stirred and heated to $90^{\circ} \mathrm{C}$ until a viscous and transparent suspension was reached. After cooling to $30^{\circ} \mathrm{C}$ in a water bath to avoid polymerization, the washed cells were added to give a ratio of $80: 20(\mathrm{w} / \mathrm{w})$.

The inner glass surface (approximately $50 \mu \mathrm{m}$ in diameter) of a capillary tip (soda lime glass) was covered at the tip with silane GR-91 (1\% in distilled water; Wacker, Germany). The capillary was dried for $5 \mathrm{~h}$ at room temperature and exposed for $1 \mathrm{~h}$ to $120^{\circ} \mathrm{C}$ to obtain a strong link between the silane and glass surface. The silane was covered with a layer of $8 \%$ PVA and dried again for $1 \mathrm{~h}$ at $120^{\circ} \mathrm{C}$. The tip was then filled with the immobilized cells. By freezing the capillary for $12 \mathrm{~h}$, a strong connection between the different layers was achieved (Myoga et al. 1991). The capillary was stored in the mineral salt medium prior to use. Finally, the tip of a self-constructed Clark-type microelectrode (Revsbech 1989) was placed into the capillary and
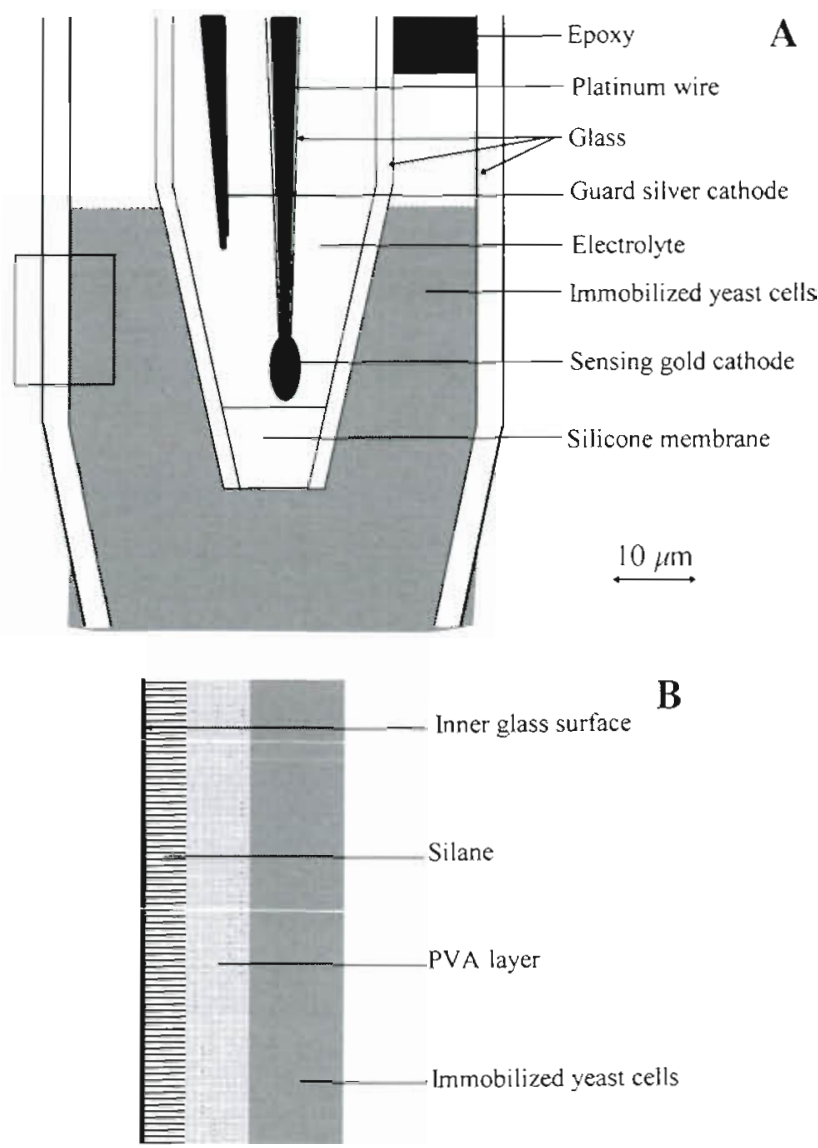

Fig. 1. (A) Schematic diagram of the tip of the biosensor. (B) Sequence of the different layers (enlargement from $A$ ). For details see text

fixed on one side with epoxy under a dissection microscope (Fig. 1).

Physical entrapment in porous polymeric carriers is widely used for the immobilization of whole cells (e.g. Karube \& Sangmok Chang 1991, Hartmeier 1994). The cells are retained in the porous network while a high porosity exists for the transport of substrates and gases which is mainly controlled by diffusion (Westrin \& Axelsson 1991). Gel structures with a defined porosity can be achieved using a variety of inorganic and organic chemical compounds either by polymerization or precipitation (Blum \& Coulet 1991). Natural substrates like agar, alginate and pectinate are often unstable and might be used by the microrganisms as a carbon source. High concentrations of sodium and calcium might cause damage to organic matrices (Weil \& Ramsch 1993). Due to its inert characteristics, we chose PVA as a matrix.

Silane GF 91 was suitable as a mediator to connect the PVA matrix to the inner surface of the capillary. Without silane the matrix detached from the glass surface within a few days. It was advantagous to cover the 


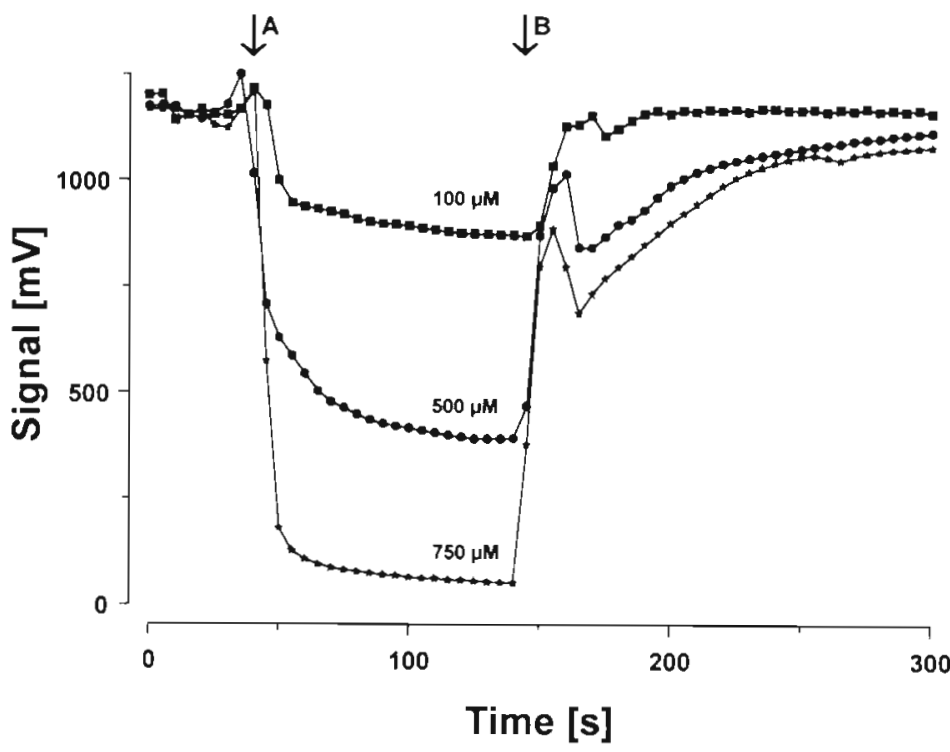

Fig. 2. Response curves of the biosensor to different concentrations of glucose. When the biosensor was removed from the mineral salt medium (saturated with oxygen) and immersed in a mineral salt medium supplemented with glucose, the immobilized yeast cells started to utilize glucose $(\downarrow A)$. As a result of respiration the concentration of oxygen and consequently the signal decreased. In the mineral salt medium without glucose, the signal returned to its initial level $(\downarrow B)$. Increasing concentration of glucose leads to increasing respiration

silane first with a layer of PVA without cells prior to the addition of PVA with immobilized cells. Drying of the silane and PVA layer at $120^{\circ} \mathrm{C}$ was necessary for a strong connection between silane and glass surface on the one hand and silane and PVA on the other hand. The final freezing step including the immobilized cells was necessary to guarantee the optimal polymerization of the matrix.

In initial experiments, 2 bacterial strains were used as test organisms for the biosensor. Both strains could metabolize glucose as the sole carbon source. However, alternative carbon sources such as acetate resulted in calibration curves which differed if carbon concentrations were extrapolated (see below). The yeast Rhodotorula mucilaginosa can metabolize 25 different $C$ sources, among them mono-, di- and trisaccharides such as glucose, maltose and cellobiose without fermentation (Heideck \& Schauer pers. comm.). Since the respiration of both substrates, glucose and acetate, resulted in comparable calibration curves normalized to carbon, we chose the metabolically versatile yeast as test organism for the biosensor.

Fig. 2 shows the response of the biosensor in mineral salt medium saturated with oxygen and supplemented with glucose. Increasing concentrations of glucose led to decreasing signals $(\mathrm{mV})$ due to increasing respiration of the test organism. The $90 \%$ response time of the biosensor was about $10 \mathrm{~s}$ when the sensor was placed in the buffer with different glucose concentration. Within 1.5 min a plateau was reached, indicating that the diffusion of oxygen from the salt medium was in equilibrium with the oxygen consumption by the yeast. When the sensor was returned to the mineral salt medium, the signal increased within $5 \mathrm{~min}$ to the initial level. This memory effect is probably caused by the glucose still remaining in the matrix and therefore available to the organisms. Glucose could be detected down to a level of approximately $50 \mu \mathrm{M}$. The biosensor was stored in mineral salt buffer at room temperature. Every second day the biosensor was immersed for $1 \mathrm{~h}$ in a buffer supplemented with glucose. By this treatment the function of the biosensor was maintained for more than $4 \mathrm{wk}$ without a loss in sensitivity and stability.

The biosensor was calibrated under in situ temperatures in mineral salt medium of different oxygen content using different concentrations of glucose ( $\mathrm{n}=5$; Fig. 3). Without glucose, a linear response typical for an oxygen sensor was obtained. Increasing concentrations of glucose resulted in curves of logarithmic shape at low oxygen concentrations. Maximum respiration rates were reached at glucose

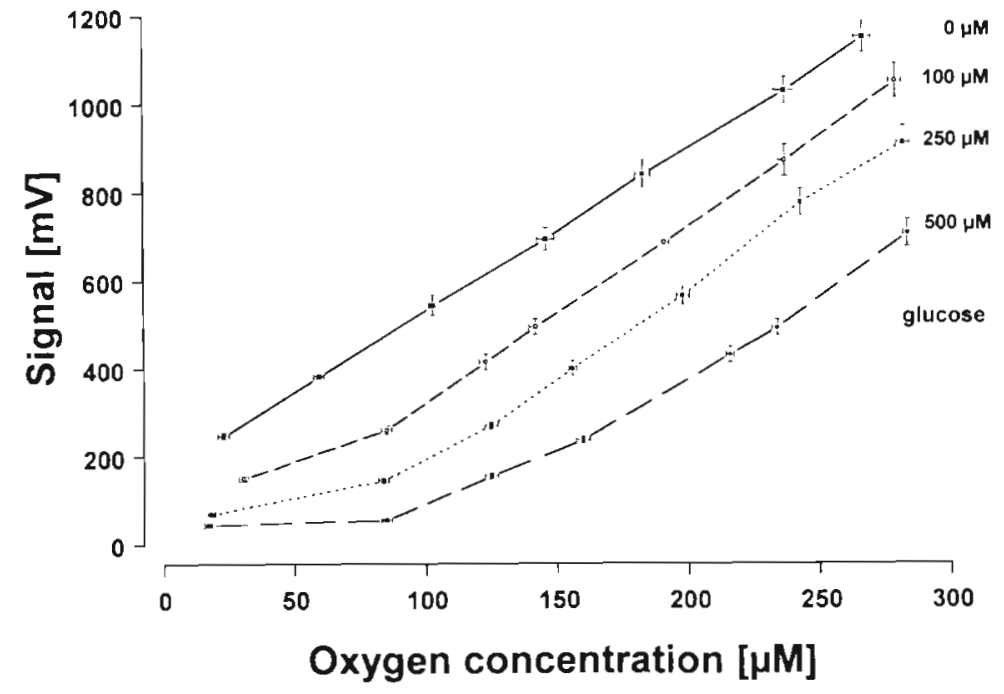

Fig. 3. Calibration curves of the biosensor using mineral salt medium of different oxygen content and different concentrations of glucose $(n=5$; CV: oxygen microelectrode $\pm 2 \%$, biosensor $\pm 5 \%$ ) 


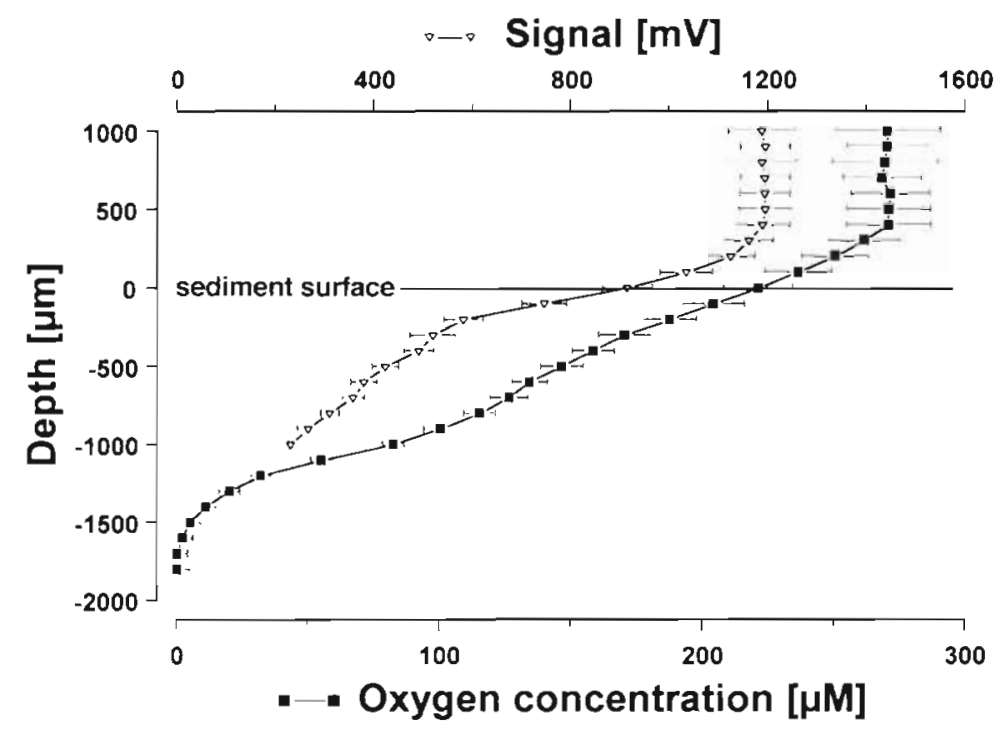

Fig. 4. Microprofiles measured in a natural sediment with an oxygen electrode and with the biosensor at the same location $(n=3, \mathrm{CV}$ : both profiles \pm 5 to $7 \%$ )

concentrations higher than $500 \mu \mathrm{M}$. The biosensor worked down to oxygen concentrations of ca $80 \mu \mathrm{M}$; at concentrations below this level, the diffusion of oxygen became the limiting factor. Calibration curves using acetate (data not shown) were comparable to glucose if carbon concentrations were extrapolated. From the calibration curves ADOC in sediment profiles of known oxygen concentrations was calculated using the following equation based on multiple regression $\left(\mathrm{r}^{2}=0.97\right)$ :

$$
\begin{aligned}
C= & 1192-492.9 \log (S)+0.066\left(\mathrm{O}_{2}\right)^{2} \\
& -0.020 \log (S)\left(\mathrm{O}_{2}\right)^{2}
\end{aligned}
$$

where $C$ is glucose concentration $(\mu \mathrm{M}), \mathrm{O}_{2}$ is oxygen concentration $(\mu \mathrm{M})$ and $S$ is biosensor signal (mV).

ADOC was analysed in sediment samples collected on May 1, 1996, in plexiglass tubes $(10 \mathrm{~cm}$ inner diameter) from the Kirr-Bucht (Darß-Zingster Bodden chain), a eutrophic shallow coastal area of the Baltic Sea (Germany). The sandy sediments were characterized by a water content of $52.3 \%$, a TOC of $1 \%$ with a $\mathrm{C} / \mathrm{N}$ ratio of 8.5 . The concentration of DOC (DOC analyser, type Astro 2100; determined courtesy of Zellweger analytics, Germany) was $18.5 \mu \mathrm{g} \mathrm{ml}^{-1}$ pore water in the 0 to $0.5 \mathrm{~cm}$ horizon.

For the analysis of ADOC, profiles with the biosensor and the oxygen microelectrode, respectively, were measured at locations as close as possible to each other (Fig. 4). The measurements ( $\mathrm{n}=3$ ) were done in pairs, first with the oxygen microelectrode, afterwards with the biosensor. The calculated coefficient of variation, $\mathrm{CV}$, was in both profiles less than $7 \%$, indicating that the sediment structure was quite homogeneous. Whereas oxygen revealed a penetration depth of approximately $1.3 \mathrm{~mm}$, the signal of the biosensor was measurable down to about $1 \mathrm{~mm}$. Below this depth the accurate measurement of the signal was limited by the low oxygen concentration (less than $80 \mu \mathrm{M}$ ). From the depth profiles of both oxygen concentrations and signals of the biosensor, ADOC was calculated using the calibration curves ( $n=3$ ). In the water above the sediment, concentrations of $\mathrm{ADOC}$ were below the detection limit. $A D O C$ values started to increase in the diffusive boundary layer approximately $200 \mu \mathrm{m}$ above the sediment, reaching maximum concentrations $\left(13 \mu \mathrm{g} \mathrm{C} \mathrm{ml} \mathrm{C}^{-1}\right.$ pore water) at a sediment denth of about 200 um Below this depth, ADOC concentrations almost continuously decreased down to about $11 \mu \mathrm{g} \mathrm{C} \mathrm{ml-1}$ at a depth of $1 \mathrm{~mm}$ (Fig. 5).

It is of special interest to compare concentrations of ADOC with TOC and respiration measurements. From the data presented, an average concentration of $6 \mu \mathrm{g}$ ADOC $\mathrm{cm}^{-3}$ sediment ( 0 to $1 \mathrm{~mm}$ depth) was calculated. Compared with $6.8 \mathrm{mg}$ TOC $\mathrm{cm}^{-3}$ sediment, this means that less than $0.1 \%$ of the TOC was immediately available. This calculation does not include the

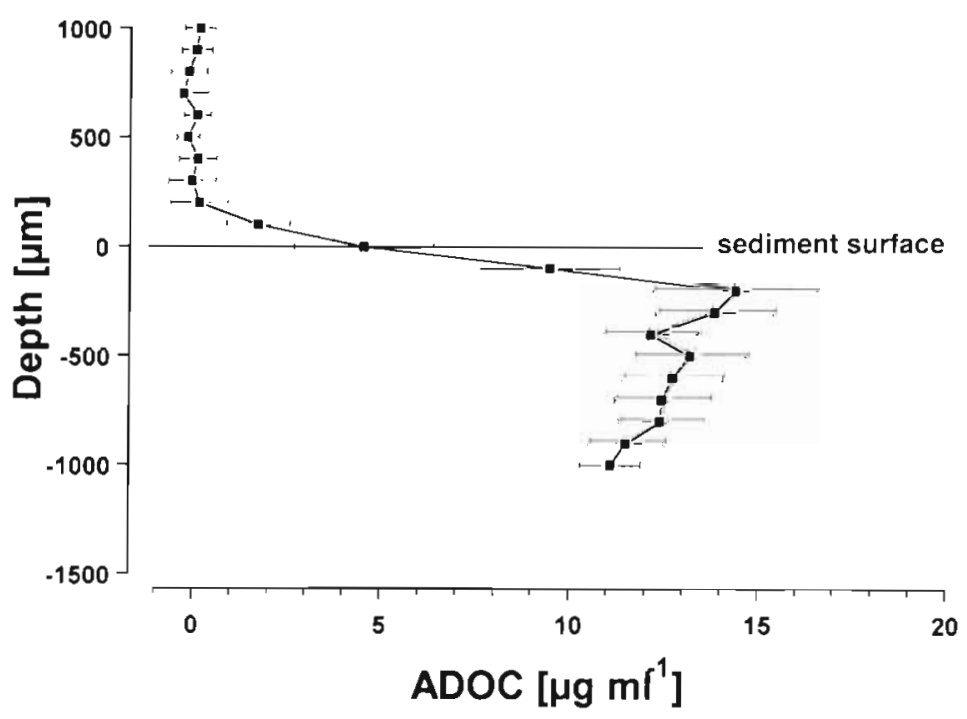

Fig. 5. Microprofile of available organic carbon (ADOC) calculated from the profiles measured in Fig. $4(n=3)$ 
fraction of TOC which is available upon hydrolysis. For surface horizons of marine sediments, values between 0.1 and $5 \%$ were reported by Nedwell (1987). Based upon comparisons of bacterial production and respiration with DOC concentrations, approximately 1 to $3 \%$ of the DOC supports bacterial growth in water samples (Coffin et al. 1993). Labile DOC pools of $<1$ to about $45 \%$ of the total measured DOC were determined by Carlucci et al. (1987). Based on the oxygen profile measured in the dark, a respiration rate of $60 \mathrm{nmol}$ oxygen $\mathrm{cm}^{-2}$ sediment $\mathrm{h}^{-1}$ was calculated in this study. Under the assumption that glucose was respired and that respiration of glucose mainly occurred in the first $1 \mathrm{~mm}$ of sediment, the carbon oxidation amounted to $7 \mu \mathrm{g} \mathrm{cm}^{-3}$ sediment $\mathrm{h}^{-1}$. Compared to the concentration of ADOC, a turnover time of about 50 min results. This corresponds to data reported in the literature on the turnover of labelled labile organic substrates in sediments (Meyer-Reil et al. 1980).

ADOC is defined with respect to the metabolic capacities of the test organisms chosen. Calculations of ADOC were based on calibration with glucose. However, the pool of ADOC comprises a variety of substrates, from which glucose represents only one source of carbon. Although corresponding ADOC values were obtained with acetate as a standard, other natural organic substrates in sediments may be oxidized with different respiration rates. Although the bioassay permits a better overall measurement of ADOC than do chemical analyses, certain limitations remain. With the experimental design described, it is not possible to measure oxygen and ADOC profiles at exactly the same location. This is a problem which is well known from investigations in which different variables are required in order to calculate concentrations of certain parameters (e.g. Revsbech \& Jørgensen 1986). Another problem is the different spatial resolution of both electrodes due to the dimensions of the tips which lead to differences in the compression of the diffusive boundary layer. It is expected that sensors with a larger tip cause larger compression effects (Glud et al. 1994). In future investigations both problems should be solved by the construction of a biosensor which combines both electrodes.

The values presented permit an estimation of concentrations of ADOC. Measurements with the biosensor are superior to other methods described, e.g. reduction of DOC during incubation or flux of organic matter deduced from biomass and mortality measurements in waters (Servais et al. 1987, 1989), growth of test organisms in filtered water samples (LeChevallier et al. 1993) or in extracts of sediments (Nedwell 1987). Compared to these methods, the advantages of determination of ADOC with the biosensor are obvious: the measurements are carried out in undisturbed sediment cores under close to in situ conditions without the disturbance of sediments and the need for incubation. the determinations of oxygen are accurate and reproducible, the high spatial resolution achieved accounts for the heterogeneity of respiration in sediments, and, finally, once the biosensor is constructed, the measurements can be performed immediately after taking the samples, yielding results in a short period of time.

Acknowledgements. This research was supported by funds from the DFG project 'Struktur- und Funktionsanalyse natürlicher mikrobieller Lebensgemeinschaften' (German Research Council; grant Me 509/5-2). We thank G. Schubert and $\mathrm{S}$. Kläber for valuable technical assistance. We are grateful to B. Heideck and F. Schauer (Department of Microbiology. Ernst-Moritz-Arndt-University Greifswald) for supplying the yeast strain. Ulrike Berninger, Steven Wickham and a number of colleagues encouraged the work through their discussions.

\section{LITERATURE CITED}

Blum 1J, Coulet PR (1991) Biosensor principles and applications. Marcel Dekker, New York

Carlucci AF, Shimp SL, Craven DB (1987) Bacterial response to labile dissolved organic matter increases associated with marine discontinuities. FEMS Microbiol Ecol 45 $211-220$

Coffin RB, Connolly JP, Harris PS (1993) Availability of dissolved organic carbon to bacterioplankton examined by oxygen utilization. Mar Ecol Prog Ser 101:9-22

Deming JW, Baross JA (1993) The early diagenesis of organic matter: bacterial activity. In: Engel M, Macko S (eds) Organic geochemistry, Topics in geobiology. Plenum Press, New York, p 119-144

Glud RN, Gundersen JK, Revsbech NP, Jørgensen BB (1994) Effects on the benthic diffusive boundary layer imposed by microelectrodes. Limnol Oceanogr 39:462-467

Hartmeier W (1994) Yeast immobilisation - from laboratory to industrial application. BioEng 6:6-12

Karube I, SangMok Chang ME (1991) Microbial biosensors. In: Blum LJ, Coulet PR (eds) Biosensor principles and applications. Marcel Dekker, New York, p 267-301

Larsen LH, Revsbech NP, Binnerup SJ (1996) A microsensor for nitrate based on immobilized denitrifying bacteria. Appl Environ Microbiol 62:1248-1251

LeChevallier MW, Shaw NE, Kaplan LA, Bott TL (1993) Development of a rapid assimilable organic carbon method for water. Appl Environ Microbiol 59:1526-1531

Meyer-Reil LA (1993) Mikrobielle Besiedlung und Produktion. In: Meyer-Reil LA, Köster M (eds) Mikrobiologie des Meeresbodens. Gustav Fischer Verlag, Jena, p 38-81

Meyer-Reil LA (1994) Microbial life in sedimentary biofilms - the challenge to microbial ecologists. Mar Ecol Prog Ser 112:303-311

Meyer-Reil LA, Bölter M, Dawson R, Liebezeit G, Szwerinski $\mathrm{H}$, Wolter $\mathrm{K}$ (1980) Interrelationships between microbiological and chemical parameters of sandy beach sediments, a summer aspect. Appl Environ Microbiol 39 $797-802$

Myoga H, Asano H, Nomura Y, Yoshida H (1991) Effects of immobilisation conditions on the nitrification treatability of entrapped cell reactors using the PVA freezing method. Water Sci Technol 23:1117-1124 
Nedwell DB (1987) Distribution and pool sizes of microbially available carbon in sediments measured by a microbiological assay. FEMS Microbiol Ecol 45:47-52

Ramsch B, Weil G (1993) Erfahrungen mit künstlichen Polymeren als Matrix für Mikroorganismen in der Abwasserbehandlung. BioEng 6:23-30

Revsbech NP (1989) An oxygen microsensor with a guard cathode. Limnol Oceanogr 34:474-478

Revsbech NP, Jørgensen BB (1986) Microelectrodes: their use in microbial ecology. In: Marshall KC (ed) Advances in microbial ecology. Plenum Publishing Corporation, New York, p 293-352

Servais P, Anzil A, Ventresque C (1989) Simple method for determination of biodegradable dissolved organic carbon in water. Appl Environ Microbiol 55:2732-2734

This note was submitted to the editor
Servais P, Billen G, Hascoët MC (1987) Determination of the biodegradable fraction of dissolved organic matter in waters. Water Res 21:445-450

Van der Kooij P, Visser A, Hijnen WAH (1982) Determining the concentration of easily assimilable organic carbon in drinking water. J Am Water Works Ass 74:540-545

Weil G, Ramsch B (1993) Sind natürliche Polymere als Matrix für Mikroorganismen in der Abwasserbehandlung einsetzbar? BioEng 2:50-60

Wellsbury P, Parkes RJ (1995) Acetate bioavallabulity and turnover in an estuarine sediment. FEMS Microbiol Ecol $17: 85-94$

Westrin BA, Axelsson A (1991) Diffusion in gels containing immobilized cells: a critical review. Biotechnol Bioeng 38: $439-446$

Manuscript first received: September 25, 1996

Revised version accepted: January 24, 1997 